\title{
Intensive Management: a Holistic View on Organizational Factors and Performance
}

\author{
Xuanhui Liu \\ Economics and Management School, Xi'an Technological University \\ Xi'an, China. \\ xuanhui.liu@foxmail.com
}

\begin{abstract}
This artide puts forward the intensive management as a holistic view to explain the causal link between organizational factors and performance. This model analyzes the reasons of organizational performance from two dimensions: the use of performance information and management. The model is tested with a case study. The implications and future research direction are discussed.
\end{abstract}

Keywords-Intensive management, organizational factors, performance improvement, public sector.

\section{INTRODUCTION}

The causal link between organizational factors and performance has been discussed in vary disciplines. These organizational factors include organizational structure, public service motivation, leadership, innovation, organizational culture, group size, etc. Many controversial conclusions have been generated in previous research. However, there is little holistic view about how these factors influencing the organizational performance.

This article attempts to offer a new model of intensive management, which will show us a holistic view on organizational factors and performance. The article is structured like the following: the first part reviews the previous research about organizational factors and performance; the second part is to introduce the conception of intensive management; the third part attempts test this model with a case study, and the final part is conclusion.

\section{LITERATURE REVIEW}

The previous research on organizational factors and performance often get contradict conclusions. In this section, I would analyze the previous research and find out a solution to solve the problem.

Organizational structure is often taken as a control variable in organizational performance research. Normally, people might think the more complex the organizational structure is, the low organizational performance will be. But in theory, it has not been proofed yet. Scholars find that government structure has little or no effects on the municipal revenue and expenditure behavior ((Benton, 2002). In some cases, the local government took measures to reform the structure to achieve better performance. But there is still no concrete causal link (Boyne, 1992).

Group size has an indirect influence on organizational performance through the decision making and information process. For example, the researches have showed that the group size would influence the decision making and information processing procedure (Zajonc, 1966). But it is still difficult to show direct causal relationship between the group size on organizational performance.

The leadership is another factor influencing the organizational performance. On one side, some scholars find the positive causal relations between leadership and organizational performance (House, 2004). Other scholars are still questioning the results. Thomas (1988) claims that the contribution to leadership research remains controversial. The "individualist" view has been increasingly questioned by "contextualists", who emphasize the constraints that are placed on leaders by situational factors (Thomas, 1988).

Besides these efforts, some scholars attempt to combine the organizational factors and performance, such as innovations, trust, and organizational culture. For example, innovations, according to the definition of Damanpour \& Evan(1984), include administrative innovation and technical innovations. The administrative innovations include those rules, roles, procedures, and structures that are related to the communications and exchanges among organizational members and between the environment and organizational members. The technical innovation includes the new idea, new technology, new service, or new element. Trust is a complex factor related with leadership, organizational structure, decision making, organizational ru les, individual attitude educational level, and so on. Organizational culture contains more elements, it is composed of the basic assumptions and beliefs that are shared by members of organizations (Grosenick and Gibson, 2001). But how to combine these factors in the management process is not clear.

In fact, these organizational factors could be put into one big category-the organizational resources. The research above attempts to identify the relationship between organizational resources and performance. From philosophical perspective, there is no mistake in these 
detailed sectors discussions. One tiny part will influence the quality of whole thing. But in an organization, these tiny parts are organized by management. If we discuss the influence of organizational resources without management, it will be problematic in the epistemology. The above researchers have a common trait: they assume other factors would keep unchanged or cooperate perfectly. Based on this premise, they construct their causal link model between organizational factors and performance. But this assumption does not exist in reality. We need to import intensive management into the analysis, which might be helpful to give us a holistic model on this is sue.

\section{DEFINITION OF INTENSIVE MANAGEMENT}

Intensive management is a conception derived from economic field. In the agricultural economics, intensive farming or intensive agriculture is an agricultural production system characterized by a low fallow ratio and the high use of inputs such as capital, labor, or heavy use of pesticides and chemical fertilizers relative to land area (Encyclopedia Britannica, 2012). It is a word opposed to extensive farming. Increased population pressure and demand for food, and shifts from small-scale independent producers to large-scale agribusinesses, have all helped drive the intensification of global agriculture (Tudge, 2004).

The conception of intensive management gets inspiration from intensive farming. Here, the intensive management refers to the approaches in management, which intensified the use of resources in the organization to improve output. The resources include human resource, facilities, capital, organizational structure, organizational culture, or anything can be used to improve output. We summarize the characteristics of intensive management in two points: first, the organizational resources are reorganized and used in more efficient manner; second, the management is intensified. Here, reorganizing means any measures to making efficient use, including adjusting the organizational structure, re-distributing the human resources, modifying the institutions, and so on. The management intensification might reach through innovation, transitional leadership, or organizational cultures. Therefore, we believe that the effective use of organizational resources and the extent of management are two essential variables influencing the organizational performance.

Based on the above analysis, we construct a model of intensive management. It is showed in Fig. 1.

\begin{tabular}{c|c|c|}
\cline { 2 - 3 } High & III & IV \\
\cline { 2 - 3 } Low & I & II \\
\cline { 2 - 3 } & \multicolumn{2}{|l|}{$\begin{array}{l}\text { Low High } \\
\text { Management }\end{array}$}
\end{tabular}

Figure 1. The Model of Intensive Management
In the first dimension of the matrix, the use of resources and management are both low. That is the characteristics of extensive farming. In the performance management process, it is a loose management or a situation in anarchy. In the second dimension, the management is intensified, but the use of resources is still low. In theory, it would be inefficient because the resources are not fully used. The potentials of the organization are not fully discovered. In the third dimension, organizational resources get fully used while the management is low. It is the situation in some democratic regimes. The citizen participation is high. The government structure is well organized. But the management could not catch up with the requirement of new situation. Therefore, the efficiency is still low. It could explain why some organizations with excellent resources but poor performance.

Only in the fourth dimension, both sectors are strengthened. It is the ideal type intensive management. The resources are used effectively according to the requirements of performance-orientated management. Meanwhile, management is intensified. The two factors cooperate to improve organizational performance. Finally, the upward spiral and virtue circle between management and performance improvement are constructed in the organization.

\section{INTENSIVE MANAGEMENT IN PRACTICE}

In this section, we will apply the intensive management model to explain the best practice in performance management. This case is a best practice of performance management in Chinese local government. In order to explore the reason of why some government departments are doing well in performance measurement while others not, the comparative case study method is employed. During the case selection process, I have scanned 405 local government departments on the is sue of performance management. The case selection is based on the criteria of efficiency and people's satisfaction. Government Affairs Service Center of Xi'an occurred as the best practice (shorted as Service Center). Compared with the performance before the establishment of Service center, the current average processing time of each approval procedure reduced $30 \%$. The satisfaction rate is $98 \%$. The efficiency has been improved dramatically in those administrative approvals which need to be done in different government departments .

Why could the Service Center achieve great changes in performance? I summarize the reasons as intensive management, which strengthened the use of resource and management. In the dimension of the use of resources, reforming the organizational structure is an important step. In order to improve the efficiency of administrative approval procedure, 31 scattered municipal functional departments were gathered together in the Service Center. The structural change plays fundamental role in the efficiency improvement. The organizational structure of 
Service Center can be divided into two big categories: the front stage and the back stage. The front stage includes the accredited departments from 31 municipal government departments. They are mainly responsible for the administration approval affairs. The back stage is responsible for internal management and service. Through structure reform, the barriers of fully use organizational resources are abolished.

Beside the reform in government structure, further measures are taken by the Service Center to improve the organizational performance, including the performance regulations, procedure standardization, and organizational culture construction. Very strict performance measurement regulations have been set up in the Service Center. The contents of performance measurement regulations cover every corner of the daily work and employees' behavior. Procedure standardization is another innovation based on the structure reform. Based on observation and practice, a standard administrative approval procedure is established to the specific administrative procedure. Such a standardization of administrative procedure has more implications for government management. First, it is a good starting point of scientific management. Each sector of the approval procedure must have specific person who will be responsible for the job. It would be easier to trace the problem. From the management perspective, it makes clear the responsibility of each government employees. Second, the performance measurement regulations would be easy to implement. The Service Center uses the modern technology to manage and supervise the performance of each employee. The direct result is that the working efficiency is improved.

Meanwhile, the Service Center has a distinguished organizational culture, which is "love the customers, love your colleagues, and love the Service Center." The organizational culture integrates the measures of management, leadership, administrative ethics, organizational learning process and the institutions together.

We could use the intensive management model to put all these factors together. Firstly, the innovations in government structure and other measures mentioned above have a common objective. That is to intensify the use of organizational resources. Secondly, compared with the extensive management in these government departments before structural change, the measures in Service Center intensified the management. Performance regulations, administrative ethics, and organizational culture intensified the management control over employees and leaders from different dimensions.

The advantages of intensive management in Service Center can be presented in four points. In the following part, I would analyze them respectively.

First, it improves the working efficiency. Compared with the extensive management, the improvement of intensive management is magnificent. According the report of People's Daily (2011), the construction admin istrative approval procedure would take 3 years or even 7 years before the establishment of Service Center, now it only needs 45 days. Since the different departments were gathered together in the service center, the impossible coordination becomes possible. For example, the simultaneous approval, which was impossible previously, now could be handles through the round table meeting. The related departments are called together and approve the application at same time. Furthermore, some scientific management approaches could be applied during this process.

Second, the intensive management increases the transparency. Since all the departments were gathered in the same hall without the wall, the whole procedure is under the supervision of customers. Meanwhile, the standardization of the procedure also increases the transparency. Modern technology is another approach to increase the transparency. The customers could trace the approval procedure on the Service Center website. On the other hand, the intensive management strengthened organizational learning between different departments. The performance-orientated culture was established through organizational learning and competition. We can find that intensive management has profound influences on organizational performance.

Third, it shows the customer-orientated service in the government. The traditional management is government-centered. In the intensive management, they could offer one-stop service to the customers. The customers do not need to run around between different departments. Time and resources are saved. It is helpful to improve the government accountability.

Fourth, it has profound meaning for performance management in the public sector. Since the New Public Management School was noticed by the scholars in 1980s, more and more enterprise management methods have been applied in the government performance management. Is it possible to carry out intensive management in local government or change the government structure fundamentally? If yes, how could we do it? The case of service center shows us the practice in reality. We could summarize the experiences give suggestions for other public sectors.

\section{INTENSIVE MANAGEMENT AND ORGANIZATIONAL}

\section{PERFORMANCE}

Damanpour \& Evan (1984) claim that the organizational innovation can be classified into admin istrative innovation and technical innovation. The technical innovation refers to those innovation occur in the technical system of an organization and are directly related to the work. The administrative innovations are those occur in the social system of an organization, which include the rules, roles, procedures and structures that are related to the communication and exchange among people and between the environment and people (Damanpour \& Evan,1984)). Here, we can find that intensive management 
is more than administrative innovation. It changes not only the procedure and structure of the organization, but also the foundation of technical innovation. In essence, the intensive management integrates organizational resources and administrative innovations in the management process.

What is the relationship between intensive management and organizational performance? Not all the management will lead to high performance. There are many influencing factors in the middle of management and performance. The results of intensive management depend on the cooperation of these factors, for example, the leadership, organizational learning, organizational culture, and so on. In this sense, we can classify the intensive management into low level and high level. The low level intensive management focuses on increasing the input and investment or change the organizational structure but pay little attention to management innovation. The high level intensive management will pay more attention to both sides, especially the innovation in rules and procedure, or so called "soft power" in the organization.

\section{IMPLICATIONS FROM THE CASE ST UDY}

The experience of Service Center tells us that we could put the different functional departments together and improve the organizational performance through intensive management. The case study identifies that the intensive management model could work successfully in practice. It has profound implications for management. The organizational performance is determined not only by the organizational factors, but also the management process. It does not matter with the size of the organization, organizational structure, institutions, or the other organizational resources, how to organize these factors will also influence the results of performance improvement.

The intensive management process is not only a process of strengthening the management control, but also a process of integrating the organizational resources into performance-orientated culture. Transparency of decision making, trust, and organizational learning are not only the by-products of intensive management, but also the effectiveness of intensive management.

Regarding to the service-orientated public sector reform, we might learn a lot from the intensive management. All the service functions can be contained in one big department, like a supermarket. The different customers could select their service freely. Through the intensive management, we could offer the citizens high quality public service with organizational structure reform and other innovations.

\section{DISCUSSIONS AND CONCLUSION}

The best practice has tested the model of intensive management. As we know, the intensive management can be classified into low level and high level. The sustainable organizational performance improvement can only be achieved at the high level of intensive management. In our model, that is the fourth dimension. From the best practice, we find that the organizational structure plays fundamental role in the process. The performance regulations, professional training, leadership, and organizational culture also have their functions in this process. The best organizational performance could only be achieved with the perfect cooperation between the different organizational resources and management. To some extents, the intensive management is a kind of management control. It could work well in Chinese cultural background. We have not tested the intensive management model in other cultural context yet. The further research might follow this direction and enrich our management knowledge in the future.

\section{REFERENCES}

[1] Benton, J. Edwin. (2002). County Service Delivery: does government structure matter?Public Administration Review, 62(2): 471-479.

[2] Boyne, George A. (1992). Local government structure and performance: lessons from America? Public Administration, 70(3): 333-357.

[3] Damanpour, F. \& Evan, W. M. (1984). Organizational Innovation and Performance: The Problem of "Organizational Lag". Administrative Science Quarterly, 29 (3):392-409.

[3] Encyclopedia Britannica, 2012. http://www.brit annica.com/EBchecked/topic/289876/int ensive-agr iculture

[4] Grosenick, L. E. \& Gibson, P.A. (2001). Governmental ethic and organizational culture. in Terry L. Cooper (Eds. ) Handbook of administrative ethics, 2nd ed., Marcel Dekker Inc.

[5] House, Robert J. et al.(2004). Culture, leadership and organizations: the globe study of 62 societies. Sage publications.

[6] Thomas AS. (1988). Does leadership make a difference to organizational performance? Administrative Science Quarterly33: 388-400.

[7] Tudge, C. (2004). So shall we reap: what's gone wrong with the world's food - and how to fix it, 2nd edn. Penguin Books, London.

[8] Verba, S. (1961). Small Groups and Political Behavior: A Study of Leadership. Princeton, N. J.: Princeton University Press.

[9] Zajonc, R. B. (1966). The Process of Cognitive Tuning in Communication. Journal of Abnormal and Social Psychology 61:159-167. 